\title{
Clinical, Refractive and Histological Reversibility of Corneal Additive Surgery in Deep Stroma in an Animal Model
}

\author{
Lucía Ibares-Frías, Patricia Gallego, Roberto Cantalapiedra-Rodriguez, Jesús \\ Merayo-Lloves \& María Carmen Martínez-García
}

To cite this article: Lucía Ibares-Frías, Patricia Gallego, Roberto Cantalapiedra-Rodriguez, Jesús Merayo-Lloves \& María Carmen Martínez-García (2016): Clinical, Refractive and Histological Reversibility of Corneal Additive Surgery in Deep Stroma in an Animal Model, Current Eye Research, DOI: 10.3109/02713683.2015.1114652

To link to this article: http://dx.doi.org/10.3109/02713683.2015.1114652

\section{Published online: 18 Feb 2016.}

\section{Submit your article to this journal $\sqsubset$}

Ш Article views: 4

Q View related articles $\asymp$

View Crossmark data ¿ 


\title{
Clinical, Refractive and Histological Reversibility of Corneal Additive Surgery in Deep Stroma in an Animal Model
}

\author{
Lucía Ibares-Frías a,b, Patricia Gallego o,c, Roberto Cantalapiedra-Rodriguez ${ }^{\mathrm{c}}$, Jesús Merayo-Lloves ${ }^{\mathrm{a}, \mathrm{d}}$, \\ and María Carmen Martínez-García ${ }^{\mathrm{a}, c}$ \\ aOptical Diagnostic Techniques Group, Theoretical, Atomic and Optical Physics Department, University of Valladolid, Valladolid, Spain; \\ 'Ophthalmology Department, Hospital Clínico Universitario de Valladolid, Valladolid, Spain; 'Cell Biology, Histology and Pharmacology Department,

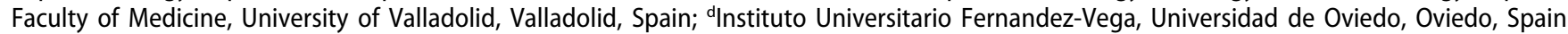

\begin{abstract}
Purpose: The aim was to evaluate the reversibility of the clinical and histological changes induced in the corneas of an animal model after removing an intracorneal ring segment (ICRS).

Methods: Surgery for this study was performed in 38 eyes of an experimental animal model (Gallus domesticus) for ICRS surgery (Ferrara technique). The animals without complications were randomized to two groups; in all of them, 1 segment was implanted in each eye and later removed at different times ( 1 and 3 months after implantation). In each group, after explantation, corneas were processed at different times for histological analysis with hematoxylin and eosin (H\&E) stain and electronic microscopy. The refractive state of the eyes was also measured.

Results: In corneas without complications (88.23\%), explantation was performed correctly. During the first few days, around the area where the ICRS was implanted we observed deposits of cells and a moderate degree of corneal opacity (haze). These signs decreased progressively without disappearing completely. Histologically, at 7 days, we observed hyperplasia and abnormal arrangement of collagen fibers. Later, these findings also decreased in both groups, albeit at a faster rate in group 1. Minimal changes were observed in electron microscopy up to the end of the study in both groups. Preoperative refractive state was achieved at 1 month after explantation in both groups.

Conclusions: ICRS can safely be explanted from the cornea. Refractive reversibility was achieved at 1 month after explantation. However, the clinical and histological findings after ICRS explantation depend on the time from implantation to explantation.
\end{abstract}

\section{ARTICLE HISTORY}

Received 28 March 2015

Revised 08 October 2015

Accepted 28 October 2015

\section{KEYWORDS}

Additive surgery; corneal wound healing; intrastromal corneal ring segments; keratoconus; reversibility

\section{Introduction}

Intrastromal corneal ring implantation has been described as a reversible, re-adjustable technique for the treatment of keratoconus, ${ }^{1}$ pellucid marginal degeneration, ${ }^{2}$ iatrogenic corneal ectasias, ${ }^{3}$ postkeratoplasty astigmatism, and slow and moderate myopias in thin corneas. ${ }^{4}$

Few studies have confirmed the reversibility of this surgery ${ }^{5-9}$ although this factor is a frequent concern in the context of ICRS implantation. The results of most of these studies were obtained from complications in clinical trials, some of which were multicenter studies, such as the U.S. Food and Drug Administration clinical trials for INTACS for myopia. ${ }^{5,6}$ The main reason for explantation of the segments in these patients was visual symptoms, ${ }^{5,7}$ followed by insufficient correction of refractive error. ${ }^{8}$ In other patients, the segments were explanted after clinical complications, such as corneal neovascularization. ${ }^{9}$ The number of patients included in these reports, however, is quite small, and no studies have focused on confirming and explaining the reversibility of this surgery.

These human studies show refractive, keratometric, topographic and visual acuity reversibility after intrastromal corneal ring explantation at 3 months postspontaneous extrusion or explantation surgery ${ }^{5,7-9}$ Aside from these few studies on the clinical, optical and refractive effects following ICRS explantation, there is little information on histo-pathological changes and wound healing and the majority are secondary to complications. ${ }^{10-12}$

Few studies in ICRS surgery in experimental animal models have been published, some using the rabbit as an animal model${ }^{13,14}$ and other in hens ${ }^{15}$; none explain the reversibility of ICRS.

Due to the scarcity of human cases studied, and the small number of histological samples analyzed without specific immunofluorescence studies to show the complete wound healing response, we propose the hen as an experimental animal model to study the specific mechanism of ICRS reversibility. Macroscopic and microscopic characteristics of the hen's cornea are reasonably similar to that of humans, having the same number of layers and proportions, therefore, composition of the collagen fibers and the Bowman layer is also similar. ${ }^{16}$ However, there are some differences with regard to the human cornea: first, the cornea is thinner and the diameter is smaller in hen corneas; second, in the hen cornea the collagen lamellae are arranged differently at

CONTACT Lucía Ibares-Frías luciaibares@gmail.com Ophthalmology Department, Hospital Clínico Universitario de Valladolid, Calle de Ramón y Cajal 3, Valladolid 47005, Spain.

(C) 2016 Taylor \& Francis 
different depths ${ }^{17}$; third, hen corneas have a special accommodation mechanism and the wound healing response is quicker than humans. ${ }^{18}$ Despite these differences, the hen has been used as an animal model to study wound healing after different surgeries in several studies carried out by us $^{19,20}$ and also by other groups. ${ }^{16,21}$ These studies have validated the hen as an animal model due to similarities to human wound healing mechanisms following PRK, LASIK and ICRS implantation.

No studies have yet explored the clinical, histological, optical and refractive responses after implantation and explantation of intrastromal corneal ring segments at different times. For this reason, it is important to study the possible reversibility of the clinical and histological changes to the cornea after this procedure, not only to gain greater insight into how the cornea reacts to surgical damage, but also to understand how it reacts to other damage of different origin that also causes deep stromal fibrosis.

The aim of this study, therefore, is to describe the wound healing process after intrastromal corneal ring implantation and explantation at 1 and 3 months postsurgery. We also correlate these changes with the clinical, refractive and optical events described in humans.

\section{Materials and methods}

\section{Animals}

The Animal Ethics and Welfare Committee of the University of Valladolid approved the animal studies described in this research. Animals were cared for following the guidelines of the Association for Research in Vision and Ophthalmology (ARVO) Statement for the Use of Animals in Ophthalmic and Vision Research. Nineteen Iber Braun adult hens (38 eyes), Gallus domesticus (weight $2.5 \mathrm{~kg}$ ) aged 6 months, were used. Both eyes of each hen were used for ICRS implantation.

\section{Anesthesia}

The hens were anaesthetized with an intramuscular injection of ketamine hydrochloride $(37.5 \mathrm{mg} / \mathrm{kg}$; Ketolar, Parke Davis $\mathrm{SA}$, Barcelona, Spain) and xylazine hydrochloride $(5 \mathrm{mg} / \mathrm{kg}$; Rompun, Bayer, Leverkusen, Germany) followed by topical application of $0.5 \%$ tetracaine chlohydrate and $1 \mathrm{mg}$ oxybuprocaine (Colircusi Anestésico Doble, Alconcusí SA, Barcelona, Spain). The animals were euthanized by an intracardiac injection of pentobarbital while under general anesthesia.

\section{Groups of animals}

The hens without complications were divided in two groups according to time to segment explantation. In group 1, the segment was explanted at 1 month postimplantation $(\mathrm{n}=16$ eyes), and in group 2 at 3 months ( $\mathrm{n}=18$ eyes).

The hens were sacrificed at 2 hours, 7 days, 1, 2, 3 and 6 months from explantation in both groups. Hens with complications were studied in a different group and sacrificed quickly to avoid animal suffering.

\section{Surgeries}

\section{Implantation of intrastromal segments}

The surgery was carried out under general anesthesia according to the mechanical method devised by Ferrara and adapted to the animal model characteristics. ${ }^{22,23}$

\section{Segment explantation surgery}

Similarly to the implantation procedure, a wire lid speculum was positioned to maintain the eye open during surgery. The same circular Ferrara marker was used to draw the circles previously described. Following this, a diamond knife was used to make a radial incision measuring $1.8-2 \mathrm{~mm}$ at the site of the previous incision (at 6 o'clock, between the 5 and $7 \mathrm{~mm}$ circles), to the same depth. Then, using a modified Suarez Spreader, the stromal pockets were re-opened in clockwise and anti-clockwise directions to the end of each segment. The Sinskey Hook was placed inside the channel in the same direction as the segment was implanted, with its tip inserted into the segment-positioning hole. The segment was removed with circular movements. After both surgeries a drop of 5\% Povidone Iodine ophthalmic solution was applied in the conjunctival sacs (video 1).

\section{Clinical course}

The corneas and anterior segments of the animals were evaluated under a surgical microscope (M220 F12, Leica Microsystems, Nussloch, Germany) before and after intrastromal segment implantation and explantation. The animals were observed at 24, 48, and 72 hours, 7 and 15 days, and later once a month after implantation and explantation surgeries, depending on time to explantation and sacrifice. Epithelial wound closure with sodium fluorescein (Fluotest $^{\circ}$, Alcon Cusi, Barcelona) was evaluated as a study parameter every 8 hours until complete epithelial closure. Edema in the central cornea was assessed as absent, minimum, medium, moderate, and severe and graded on a scale of 0-4. Deposits that developed in association with the segments were graded on the Ruckhofer scale ${ }^{24}$ from 0 for no deposits to 4 for severe, fully confluent deposits covering the entire channel width that obscured visualization of the underlying structures under diffuse illumination. Haze was also graded on a 1-4 scale according to Fantes. ${ }^{25}$ Complications such as corneal neovascularization, abscess, infiltrates, melting corneal ulcers, and extrusions were also described.

\section{Pachymetry}

Central corneal thickness was measured with an ultrasonic pachymeter (Corneo-Gage Plus, Sonogage Inc, Cleveland, $\mathrm{OH})$ before and after ICRS implantation and explantation, daily during the first week, once a week during the first month, and then once a month.

\section{Optical measurements: Refractive state}

The refractive state was evaluated with an automated eccentric infrared photorefractor adapted by Schaeffel for measurements 
in chickens. ${ }^{20}$ The highest hyperopic value at which the retinal reflex was reversed was taken to be the resting refraction. Refractive state measurements were taken preoperatively at 1,2 , and 3 months postimplantation and 1,2, 3, 4, 5, and 6 months postexplantation. Refractive measurements were taken with the animals awake and under mesopic viewing conditions as previously described. ${ }^{26}$

\section{Tissue processing and light microscopy}

All eyes were exenterated and fixed with $10 \%$ buffered formalin for 24 hours, and then washed in $0.1 \mathrm{M}$ buffer phosphate and embedded in paraffin wax. Sections were stained with H\&E and periodic acid-Schiff. ${ }^{19}$ The sections were examined under an Olympus BX41 microscope (Olympus Life Science, Hamburg, Germany) and two photomicrographs of each cornea were obtained with an Olympus DP20 Digital Camera. Quantitative measurements of the photographs were taken using the program Cell A (Olympus Soft Imaging Solutions GmbH, Münster, Germany). Stromal cells were counted at $10 \times$ magnification using the Touch Count function in a total area of $10000 \mu \mathrm{m}^{2}$ in deep stroma where the ICRSs were implanted.

\section{Cell death}

To detect DNA fragmentation associated with apoptosis, terminal uridine nick end labeling (TUNEL) assays were performed using deparaffinized sections according to the manufacturer's instructions (TUNEL Ref: G3250, Promega Corp., Madison, WI, USA). Nuclei were counterstained with 4',6-diamino-2 phenylindole (DAPI) (D9542, Sigma-Aldrich, Munich, Germany).

\section{Cell proliferation}

One hour before euthanasia, the animals received an intramuscular injection of 5-bromo-2'-deoxyuridine (BrdU, Sigma-Aldrich), a marker of DNA synthesis $(10 \mathrm{mg} / \mathrm{ml}, 5$ $\mathrm{ml} / \mathrm{kg}$ ). Sections were deparaffinized and treated with $2 \mathrm{~N}$ $\mathrm{HCl}$ for 1 hour, then incubated with mouse monoclonal $\operatorname{IgG}$ anti-BrdU (Dako, Cytomation Carpinteria, CA, USA) for 30 minutes at room temperature. The secondary antibody was fluorescein goat anti-mouse IgG (1:100, Molecular Probes, Leiden, The Netherlands) in Tris-buffered saline. In control slides, the primary antibody was omitted.

\section{Differentiation of myofibroblast cells}

Myofibroblast cells were identified by staining with anti- $\alpha$-SMA monoclonal antibody (mouse clone 1A4, Dako, Glostrup, Demark). The secondary antibody was Texas red goat antimouse IgG (Molecular Probes). Sections were examined under an Axiophot fluorescence-incorporated microscope (Zeiss Axiophot HB0-50, Carl Zeiss, Germany) and photomicrographs were captured using the AxioCam HRc Digital Camera and Axiovision release 4.8 software (Carl Zeiss, German). The wall of the limbal blood vessels served as positive control, and omission of the primary antibody provided negative controls.

TUNEL, BrdU and $\alpha$-SMA positive cells were quantitatively counted in an area of $10000 \mu \mathrm{m}^{2}$ of two slides of each cornea at 10x magnification using the Touch Count function in the deep stroma where the segment was implanted.

\section{Transmission Electron Microscopy (TEM)}

The $2 \%$ glutaraldehyde and $2 \%$ paraformaldehyde fixed corneas were rinsed for 24 hours with $0.1 \mathrm{M}$ buffer phosphate and postfixed in 1\% osmium tetroxide for 1-2 hours at room temperature. The tissue was dehydrated in ascending concentrations of acetone, infiltrated with propylene oxide and embedded in Spurr resin. Semi-thin sections measuring $1 \mu \mathrm{m}$ were stained with $1 \%$ toluidine blue $/ \%$ sodium borate solution and examined under a light microscope. Selected sections were cut on a LKB ultramicrotome and examined with JEOL JEM-1011HR (Jeol Ltd., Tokyo, Japan) electron microscope. Photographs were taken with a Charge Coupled Device (Gatan, Erlangshen ES1000W) and DigitalMicrograph 1.71 Software.

\section{Scanning electron microscopy of the explanted segments}

The explanted segments were analyzed using scanning electron microscopy (SEM). Immediately after the ICRS was explanted it was fixed in $4 \%$ paraformaldehyde for 2 hours and then washed in phosphate buffer, where it remained until visualization with SEM (FEI, Quanta 200F, Holland). Electronic microscopy was performed in the Microscopy Department of the Scientific Park of the University of Valladolid.

\section{Statistical analysis}

Measured variables were analyzed by calculating the mean, median, quartiles (lower quartile and upper quartile), standard deviation (SD), coefficient of variation, maximum and minimum values, skewness, and coefficient of kurtosis. After defining these parameters, variances were compared with the Levene test. If the variances were equal, an analysis of variance (ANOVA) table was used to test the equality of the means. If the variances were different, then the non-parametric Kruskal-Wallis, test was used to compare the equality of the medians.

Moreover, a multiple range test was used to determine which means were significantly different from others.

\section{Results}

Thirty four eyes (89.48\%) had good follow up and were clinically and histologically studied.

Complications were observed in $10.52 \%$ of the eyes (4 eyes) within 1 month after implantation. Spontaneous extrusion of the segments was found in all the eyes presenting complications (in 3 eyes, with superficial neovascularization from limbus to the segment).

\section{Clinical course}

In non-complicated eyes at 1 and 3 months after implantation (when the ICRS were explanted in group 1 and 2, respectively), corneal differences were observed. At 1 month postimplantation, deposits were observed along the inner curvature of the segment (Figure 1a), and at 3 months, the severity of deposits increased 
and became more compact and closer to the segment along the inner, outer curvature and below the segment (Figure 1b, black and white arrows). In group 1, explantation was easier than in group 2. After explantation, an empty space was observed in the deep stroma where the segment had been implanted in both groups. During the first week, deposits were observed in this space (more intense and compact in group 2). Fifteen days after explantation, deposits disappeared and a stromal leucoma was observed in their place, which had not disappeared by the end of the study in both groups (Figure 1c). Changes after explantation were slower in group 2 than in group 1 .

In complicated eyes with spontaneous extruded segments, diffuse leucoma was observed at the implantation site with superficial and deep neovascularization from the limbus to the leucoma in 3 eyes (Figure 1d). After this, the intensity of the leucoma gradually decreased and new vessels became thinner, without disappearing, until the end of follow up (Figure 1e).

\section{Ultrasonic pachymetry}

Pre-surgery central and peripheral corneal thickness was $246.21 \pm 11.89$ and $317.20 \pm 22.40$, respectively. The average depth of the incision was $244.24 \pm 11.96$. This corresponded to $77.64 \%$ of the peripheral corneal thickness.

Changes in corneal pachymetry are shown in Figure 2. Both groups showed an increase in corneal thickness during the first 15 days after implantation and explantation, a statistically significant difference with regard to preoperative values $(p<0.05)$. Later, pachymetry values returned to normal in both groups, though earlier in group 1, following implantation and explantation.

\section{Refractive error}

Changes in refractive error are shown in Figure 3. Before implantation of the segments all the hens showed moderate hyperopic refractive error. After implantation of the segments, we observed a statistically significant change in refractive error $(\mathrm{p}<0.05)$ (more hyperopic). This was maintained until the scheduled explantation was performed (at 1 month in group 1 and 3 months in group 2). After explantation at 1 and 3 months, eyes returned to the preoperative state 1 month after the second surgery in both groups. This refractive state was also maintained until the end of the study.

\section{Histological findings}

\section{Haematoxylin and eosin stain}

In both groups (explantation at 1 and 3 months), partial collapse of the channels where the segments had been implanted together with the entire surrounding cellular and extracellular component was observed immediately ( 2 hours) after explantation (Figure $4 \mathrm{a}$ and d). The cellular component on both sides of the space left by the segment was composed of the same cells that were found around the segment prior to

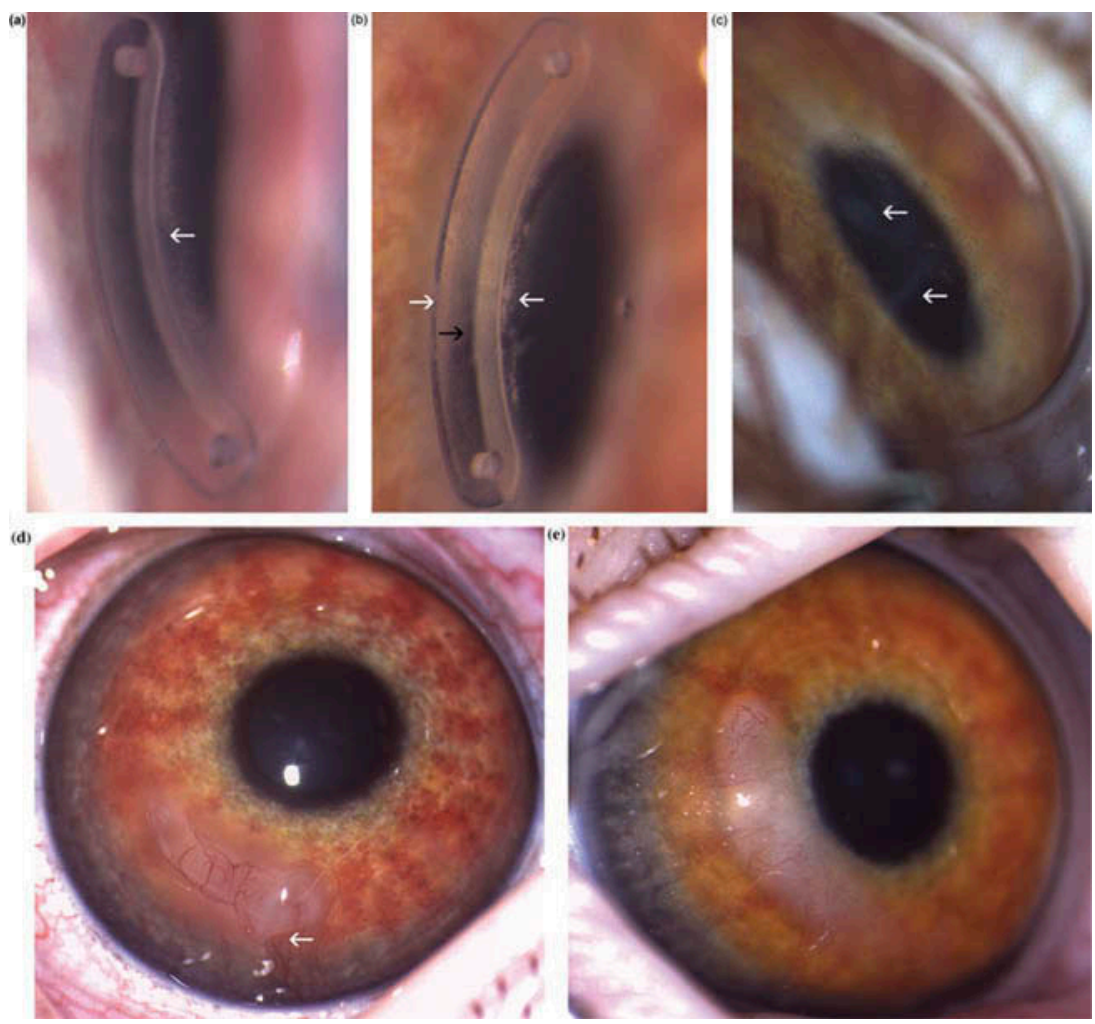

Figure 1. Clinical images of non-complicated corneas. (a) Deposits along the inner curvature of a segment implanted 1 month previously (white arrow). At 1 month the deposits were rounded and pigmented. (b) Deposits along the inner, outer curvature (white arrows) and over the segment (black arrow) implanted 3 months previously. At 3 months, the deposits were more compact and pigmented than at 1 month and were closer to the segment. (c) Cornea with controlled explanted segment showing lineal corneal haze at the site of the incision (inferior arrow) and diffuse corneal haze around the site of the segment (superior arrow). Images (d) and (e): clinical images of complicated corneas. (d) Cornea with deep and superficial neovascularization and start of spontaneous segment extrusion (arrow). (e) Cornea with extruded segment and a leucoma with neovascularization. 


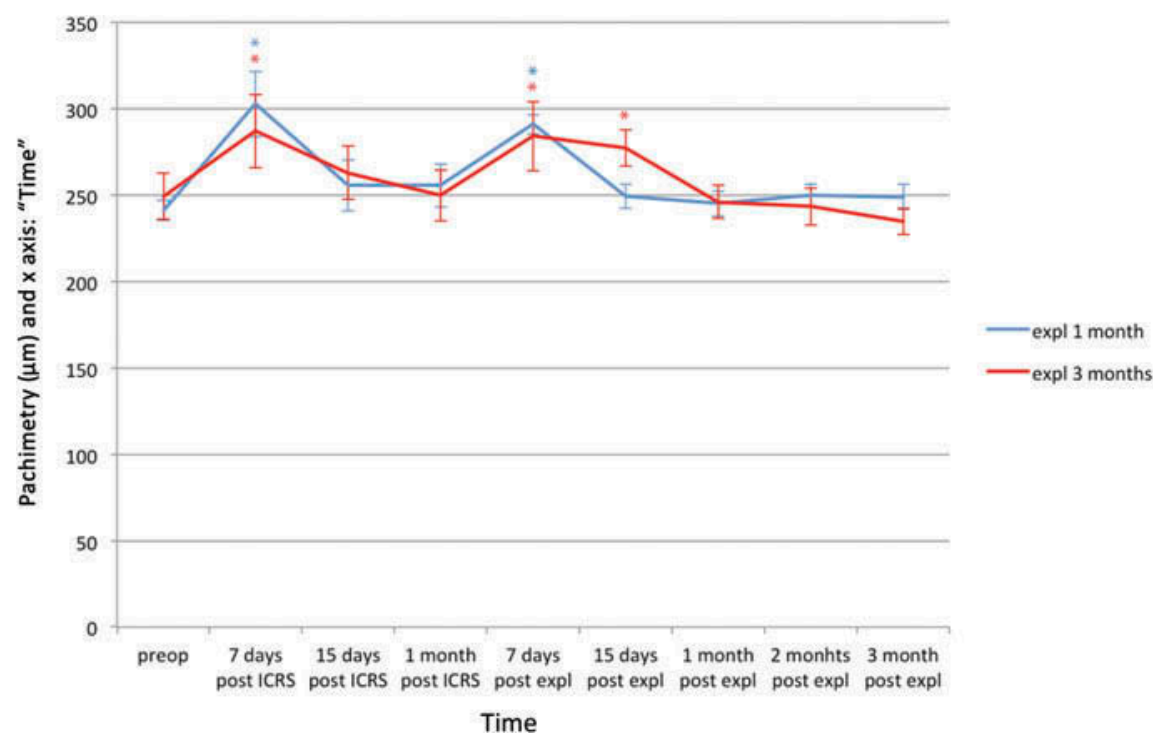

Figure 2. Pachymetry changes (represented by media and standard deviation) during follow up in group 1 (blue line) and group 2 (red line). * Values statistically significantly different with regard to preoperative values.

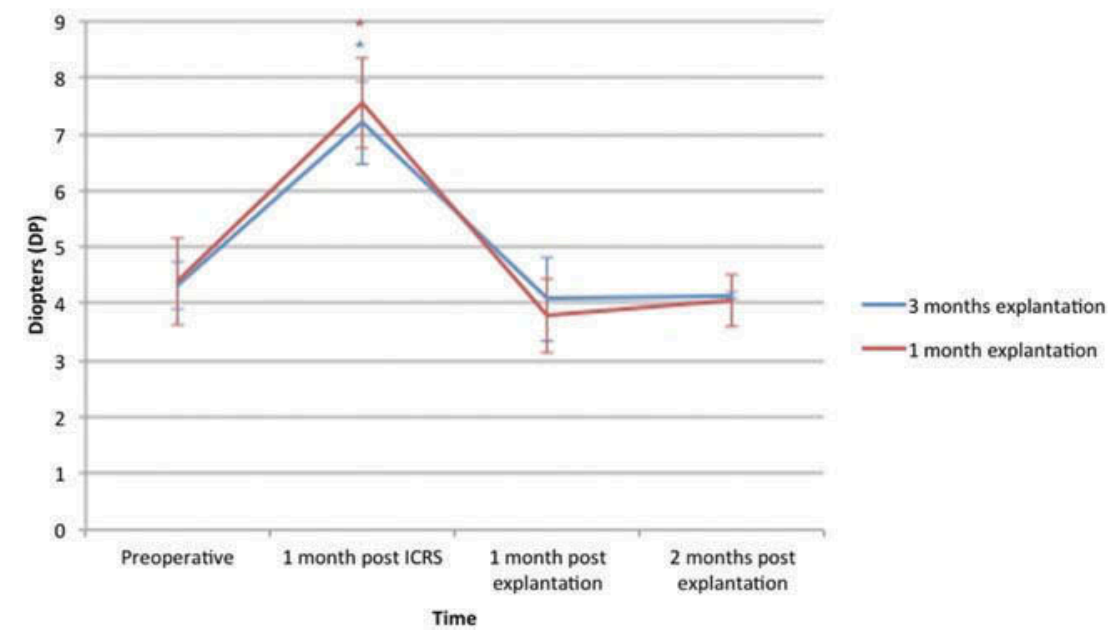

Figure 3. Graphic of the refractive state at different periods of time in explantation group at 1 month and at 3 months showing media and standard deviation. Eyes returned to the pre-operative state 1 month after explantation in both groups. * Values statistically significantly different with regard to preoperative values.

explantation. Some of these cells were fusiform and basophilic in appearance, like fibroblasts. In the first few hours after explantation, the epithelium layer in the 3-month explantation group maintained the hypoplasia described in histological preparations of ICRS (Figure 4d). In our series, this epithelial hypoplasia recovered preoperative values first in group 1 and later in group 2 (Figure $4 \mathrm{a}$ and e).

At later analysis dates, the channel in both groups was completely collapsed, and in its place two cellular deposits were found on the inner and outer edges of the scar (Figure $4 \mathrm{c}$ and e). An eosinophile extracellular matrix (Figure $4 b, c$, e, and f) was also observed around these cells. The number of such cells gradually decreased over follow up, and the morphology changed to apoptotic cells with pyknotic nuclei. Slight changes in deep stroma were observed up to 6 months after explantation (Figure 4f).

The density of cells at different times was shown in Figure 5, statistical differences with the previous times were represented by *. There were statistically significant differences between both groups in all times analyzed.

In complicated corneas, blood vessels could be seen coming thorough the anterior stroma from the limbus to the area of the leucoma where the segment had been extruded (Figure 4g, black arrows). The leucoma was composed of an eosinophilic extracellular matrix (ECM) and cells resembling fibroblasts (Figure $4 \mathrm{~h}$, black arrows).

\section{Cell death}

TUNEL-positive cells and cell debris were located in the superficial layer of the epithelium in both groups in all times where apoptosis routinely occurs prior to sloughing off the most apical cells death.

The density of TUNEL positive cells at different times was shown in Figure 6. There were statistically significant differences 


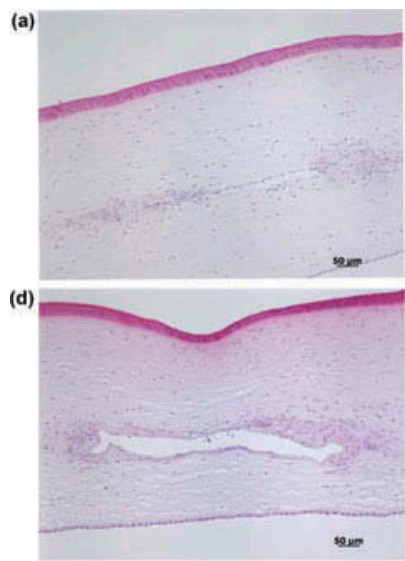

(g)
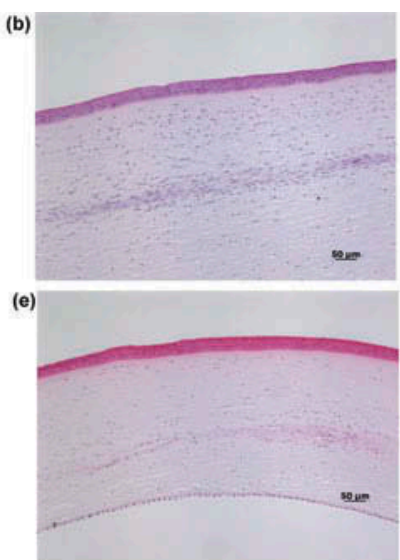

(h)

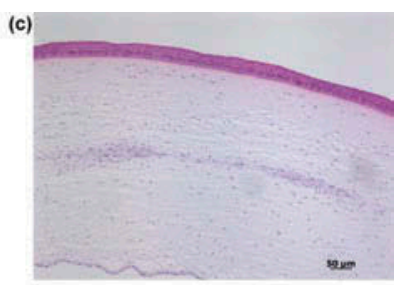

(f)

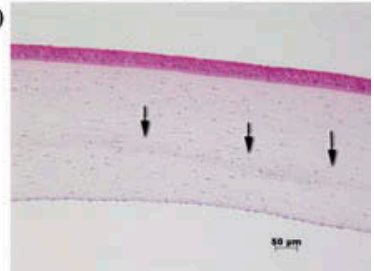

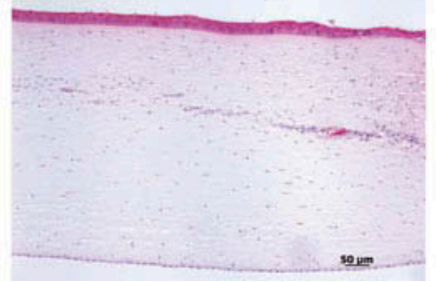

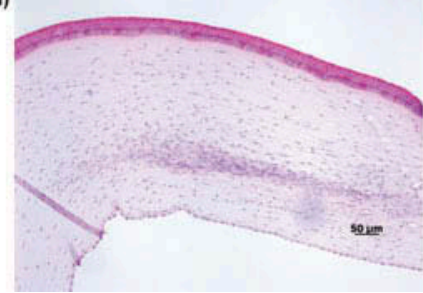

Figure 4. Hematoxylin-eosin images of corneas with explanted segments. (a) Cornea with segment explanted 1 month postimplantation at 2 hours of follow-up. (b) Cornea with segment explanted 1 month postimplantation and fixed 7 days after explantation. (c) Cornea with segment explanted 1 month postimplantation and fixed 1 month after explantation. (d) Cornea with segment explanted 3 months from implantation and fixed 2 hours after explantation. (e) Cornea with segment explanted 3 months postimplantation and fixed 2 months after explantation. (f) Cornea with segment explanted 3 months postimplantation and fixed 6 months after explantation. All histological tests show cells and new extracellular matrix in deep stroma where the segment was implanted. Images (g) and (h): hematoxylin-eosin images of corneas with extruded segments due to complications. (g) Histological image of limbal neovascularization, arrows: new vessels. (h) Histological image showing cells, new collagen and extracellular matrix in deep stroma, where the segment was implanted, arrows: new collagen, extracellular matrix and cells.

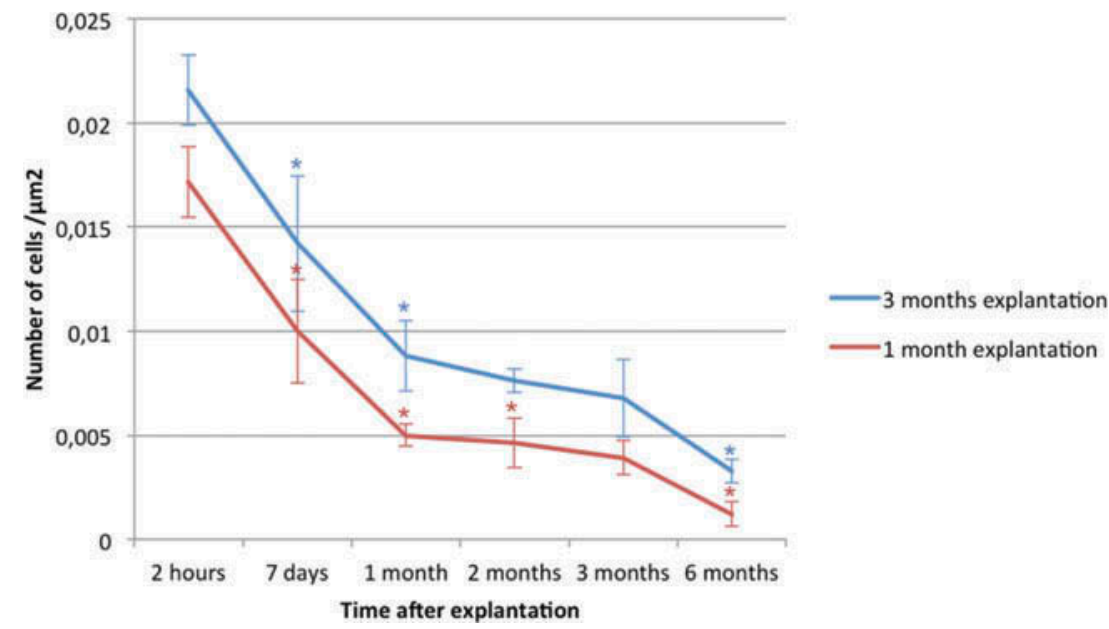

Figure 5. Density of cells in the stroma where the segment was implanted after explantation during follow up. Differences between previous time were represented by * $(p<0.05)$. Cells decreased from 2 hours to 6 months after explantation in deep stroma where the segment was implanted in both groups.

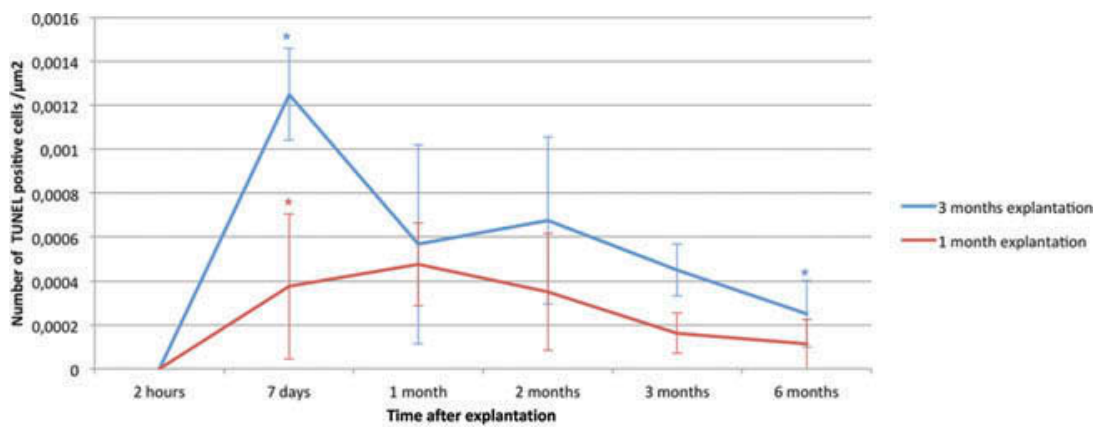

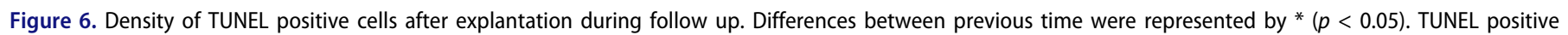
Cells decreased from 2 hours to 6 months after explantation in deep stroma where the segment was implanted in both groups. 
between 2 hours and 7 days in both groups and in group of 3 months of explantation between 3 months and 6 months $\left(^{*}\right)$. There were statistically significant differences between both groups in all times analyzed. TUNEL positive cells gradually decreased, without disappearing completely in both groups, by the end of the study.

\section{Cell proliferation}

BrdU positive cells, indicating cellular DNA synthesis, were detected in the basal layer of the epithelium at all times during follow up. However, in deep stroma, BrdU positive cells were not found at any time after explantation.

\section{Differentiation of a-SMA-positive cells}

No $\alpha$-SMA cells were found at any time in any group.

\section{Transmission electron microscopy (TEM)}

The corneas of both groups that were histologically processed after 3 months postexplantation of both groups were examined by TEM in the area of clinical leucoma.

In this area, as shown on the semi-thin slide (Figure 7a), a thick line with larger cells and more stained ECM remained. Under electron microscopy, stromal collagen was disorganized with some activated fibroblasts that contributed to the light opacity showed in the clinical signs (Figure $7 \mathrm{~b}$ and $\mathrm{c}$ ).

\section{Scanning electron microscopy (SEM) of the explanted segments}

SEM of the surface of the explanted segments in normal and complicated corneas showed deposits on the surface of all segments analyzed and at all sites. The greatest accumulation of deposits was observed in the positioning hole next to the incision and the inner curvature of the segment. More deposits were found in 3-month explantation segments than in 1-month explantation segments.

In segments explanted from non-complicated eyes 3 different structures with different morphology were observed. First, a heterogeneous non-cellular structure varying in appearance from fibrous to globular morphology (Figure 8a) was found. Cellular structures were also observed on the surface, one of which was rounded with prolongations towards the surface of the segments (Figure 8b) and the other more fusiform, similar to fibroblasts (Figure 8c).

In segments explanted from complicated eyes, in addition to the non-cellular and cellular deposits described above, (a)

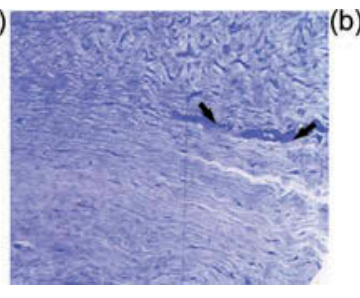

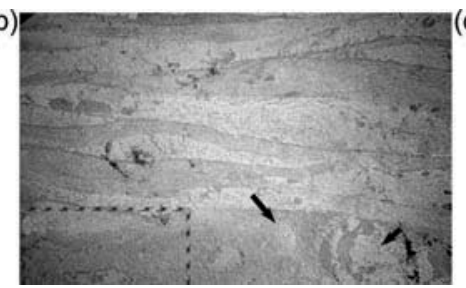

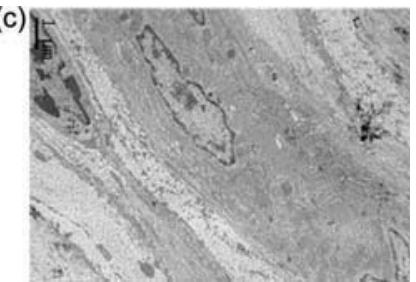

Figure 7. TEM of a cornea with segment explanted 3 months after implantation and were studied after 6 months of explantation. (a) Semi-thin section prior to ultrathin sections where the activated keratocytes are located (black arrows). (b) Lamellar disposition of collagen fibrils are located in the superficial stroma. In the deep stroma, there are activated fibroblasts and disorganized ECM (arrows). (c) Detail of activated fibroblast showing fusiform shape, nucleolus and a large rough-surfaced endoplasmic reticulum.

(a)

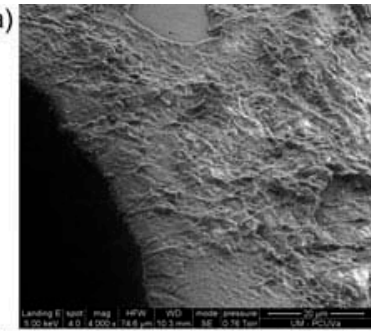

(d)

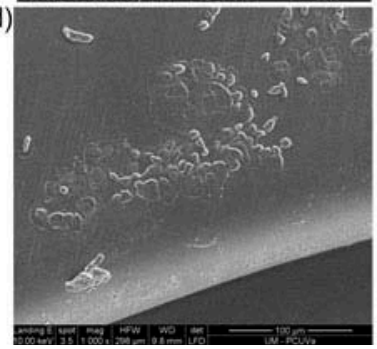

(b)

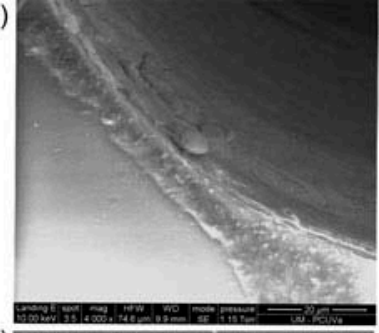

(e)

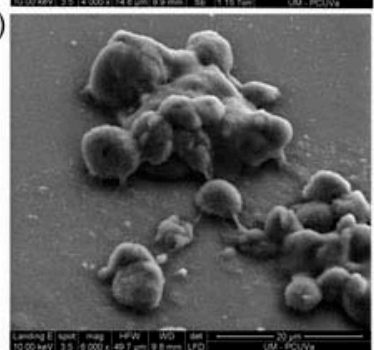

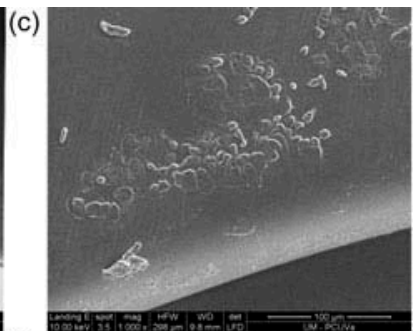

(f)

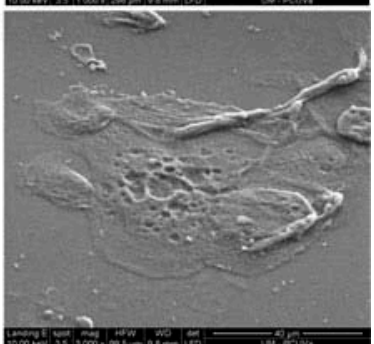

Figure 8. SEM of the deposits over the segments explanted from corneas with good follow up at 3 months. (a) Deposits of collagen fibers and extracellular matrix growing over the surface. (b) Spherical cell deposits bonded to the surface in the position hole. (c) Fibroblast-like cells over the segment. Images (d), (e) and (f): SEM of segments explanted from complicated corneas. (d) Epithelial cells over the extruded segment. (e) Spherical cellular deposits similar to lymphocytes. (f) Large cells resembling macrophages. 
epithelial-like cells (Figure 8d) were observed in the extrusion area. Other cells, smaller than those previously described, were spherical in shape with small prolongations towards the surface of the segments, with the appearance of lymphocytes (Figure 8e). Finally, another cell type was observed, this being larger, rich in cytoplasm organelles, with an irregular surface; they were probably macrophages (Figure $8 \mathrm{f}$ ).

\section{Discussion}

ICRS surgery has been often described as a reversible technique for the treatment of keratoconus, pellucid marginal degeneration, postlaser-assisted in-situ keratomileusis (LASIK), secondary ectasia, and postkeratoplasty astigmatism. ${ }^{1-3}$

The majority of the studies have described complete refractive reversibility after intrastromal corneal ring explantation, however, partial clinical and histological reversibility of this surgery has been reported in the literature. ${ }^{5-8}$ Moreover, there are insufficient data regarding the wound healing process associated with the procedure to make a significant contribution to the safety and efficacy of this refractive surgical procedure. Ethical limitations make it impossible to carry out these studies together (clinical, optical and histological) in humans, and for this reason it is necessary to develop an experimental animal model. Loghman Brown hens seem to be a useful experimental model for histological and clinical studies in wound healing processes after different corneal surgeries. ${ }^{15,19,27}$

The use of these healthy corneas could lead to a slightly different wound healing response to ectatic ones, however our findings correlate with the majority of the events described in the few human studies. Moreover, we think that wound healing in normal tissues rather than pathologic ones is the previous step to better understand better the mechanism implicated because there are less factors which could influence the histological response.

For all these reasons we propose the hen as an experimental model for this study. In this case, hens were used to study the wound healing process after explantation of Ferrara's intrastromal corneal ring segments in normal and complicated eyes.

The choice of two groups for explantation was made based on clinical, histological and refractive events described in the literature after intrastromal corneal ring implantation in animals $^{13,15}$ humans ${ }^{4,5}$ and in our previous manuscript of the tissue reaction after ICRS implantation which described the great amount of cells at 1 and 3 months. ${ }^{28}$

Extrusion or explantation of intrastromal corneal ring segments have been described as a complication in some studies in humans and in a few studies in animals. ${ }^{13,15}$ In this study, the rate of complication was similar to that reported in early studies on manual ICRS implantation in humans. ${ }^{5-8}$

The cause of spontaneous explantation after manual implantation was related in most studies to the learning curve. $^{29,31}$ Ferrer et al. (2010) found the principal cause of ICRS explantation to be extrusion with inflammatory response, concluding that extrusion could be a type of host rejection related to deposition of inflammatory cells and cellular debris seen in explanted segments under SEM. ${ }^{31}$ In 2012, however, with a lower incidence $(0.56 \%)$ of extrusion in their series, Ferrara suggests that the segment should be implanted at $80 \%$ of the corneal thickness and should not measure more than $50 \%$ of the corneal thickness in the channel to avoid extrussion. ${ }^{30}$ In our study, implantation was performed at $70-80 \%$ of corneal thickness (mean $77.64 \%$ ), with a segment thickness of $150 \mu \mathrm{m}$, less than $50 \%$ of the central thickness of the cornea $(317.20 \pm 22.40 \mu \mathrm{m})$ agreeing with Ferrara's rules. Moreover, in our study, spontaneous extrusion was preceded by neovascularization and inflammatory reaction, in line with Ferrer et al., ${ }^{31}$ but when we analyzed these complicated corneas we observed superficial implanted segments or thinner corneas, which we think were the principal cause of the spontaneous extrusion, as suggested by Ferrara et al. ${ }^{30}$

With regard to clinical follow up, a deep stromal space was immediately observed following controlled explantation, which closed during the first days with deposits, later only a residual leucoma in deep stroma was observed until the end of the study. These clinical events are similar to those reported by Quantock (1995), who found a trace of haze in deep and medial stroma at 8 months postexplantation. ${ }^{10}$ The remaining human studies were only based on clinical and refractive reversibility and did not describe any clinical modification in stroma. ${ }^{5,6,8}$

The refractive reversibility described in this study at 1 month postexplantation in both groups is consistent with the findings of other studies in humans, which report refractive error recovery from the first few days postexplantation, ${ }^{5,6,8}$ suggesting that refractive stabilization occurs from 1-7 weeks.

With regard to histological events after ICRS explantation, the first reversible change observed was normalization of the epithelial layers in both groups. ${ }^{11}$ Later, in deep stroma, the amount of cells and new extracellular matrix (ECM) which composed the scar around the segment in deep stroma began to decrease progressively without reaching preoperative values at the end of the study and with a slightly different response regarding time of explantation from implantation. Our results, showed this decrease in fibroblasts is due to progressive apoptosis and a remodeling process in the ECM (TEM). The purpose of both was to restore the normal anatomy of the cornea after explantation of the artificial material. There is no other manuscript which studies this mechanism in literature.

Electron microscopy of the cornea allowed us to evaluate very small changes in stroma. TEM studies of the samples in the area where deep stromal leucoma was found, showed some fibroblasts and alteration of the collagen arrangement, findings which concur with those described by Quantock and Ruckhofer. ${ }^{10,12}$ However, TEM findings differed from the leucocytes or lymphocytes described by Wolter et al. in their study in rabbits. ${ }^{32}$

SEM of the surface of the explanted segments provided an interesting insight into cellular reaction and wound healing of the stromal collagen some months after explantation. We disagree with Ferrer et al., ${ }^{31}$ because we found deposits and cells not only in eyes with complications but also in those without complications. This is in line with Ruckhofer, who described an amorphous substance on the surface of non-complicated segments. ${ }^{12}$ However, we also disagree with this assessment because we also found keratocyte or fibroblast cells over the segment.

On the surface of the complicated segments we also found inflammatory cells, lymphocytes and macrophages beside extracellular matrix deposits, which is consistent with Ferrer et al. ${ }^{31}$ 
In conclusion, this study describes the clinical, histological and refractive reversibility of the implantation of intrastromal corneal ring segments. Reversibility is different regarding time of explantation from implantation. Refractive reversibility was observed and clinically corneal thickness was regularized at 1 month postexplantation. However, throughout the study, a residual leucoma remained in the area where the segment was implanted. Electron microscopy studies in long term follow up of corneas after explantation showed slight changes in the deep stroma that had not disappeared by the end of the study, and must also be taken into consideration before programming further surgery. This study is important, not only because it explains and correlates clinical, refractive and histological reversibility following ICRS implantation and explantation, but also because it can be extended to other deep stromal surgical or non-surgically induced wounds. To our knowledge this is the first study on long evolution deep stromal haze after a slight wound with a minimum damage to the basement membrane with no myofibroblast generation.

\section{Acknowledgments}

We would like to thank Dr Angel García Barcia, Félix Gómez and Juanjo Arribas for caring for the animals used in this study. Ferrara Rings and AJL Ophthalmics provided both PMMA segments and surgical instruments. We would like to thanks Manuel Avellla and Luis Santiago as technical assistance from the Microscopy department of the University of Valladolid for the electron microscopy images. We would also like to thank Dr Alfonso and the staff of SECOIR (Spanish Society of ImplantRefractive Ocular Surgery) for their help during the closing stages of this study. We also thank Carmina Sanchis and Laura López Giménez from MSC for her advice on methodology. This work was supported by the CENIT-CeyeC (Customized Eye Care Technology) program, and also by profit cit-300100-2007-50 "Desarrollo de nuevos implantes intracorneales para la corrección de ametropias y tratamiento de ectasias corneales".

\section{Declaration of interests}

The authors report no conflicts of interest. The authors alone are responsible for the content and writing of the paper. All authors certify that they have no affiliations with or involvement in any organization or entity with any financial interest (such as honoraria; educational grants; participation in speakers' bureaus; membership, employment, consultancies, stock ownership, or other equity interest; and expert testimony or patent-licensing arrangements), or non-financial interest (such as personal or professional relationships, affiliations, knowledge or beliefs) in the subject matter or materials discussed in this manuscript.

\section{References}

1. Siganos D, Ferrara P, Chatzinikolas K, Bessis N, Papastergiou G. Ferrara intrastromal corneal rings for the correction of keratoconus. J Cataract Refract Surg 2002;28:1947-1951.

2. Rodriguez-Prats J, Galal A, Garcia-Lledo M, De La Hoz F, Alio JL. Intracorneal rings for the correction of pellucid marginal degeneration. J Cataract Refract Surg 2003;29:1421-1424.

3. Siganos CS, Kymionis GD, Astyrakakis N, Pallikaris IG. Management of corneal ectasia after laser in situ keratomileusis with INTACS. J Refract Surg 2002;18:43-46.

4. Rapuano CJ, Sugar A, Koch DD, Agapitos PJ, Culbertson WW, de Luise $\mathrm{VP}$, et al. Intrastromal corneal ring segments for low myopia: a report by the American Academy of Ophthalmology. Ophthalmology 2001;108:1922-1928.

5. Asbell PA, Ucakhan OO, Durrie DS, Lindstrom RL. Adjustability of refractive effect for corneal ring segments. J Refract Surg 1999;15:627-631.

6. Asbell PA, Ucakhan OO, Abbott RL, Assil KA, Burris TE, Durrie DS, et al. Intrastomal corneal ring segments: reversibility of refractive effect. J Refract Surg 2001;17:25-31.

7. Clinch TE, Lemp MA, Foulks GN, Schanzlin DJ. Removal of INTACS for myopia. Ophthalmology 2002;109:1441-1446.

8. Chan SM, Khan HN. Reversibility and exchangeability of intrastromal corneal ring segments. J Cataract Refract Surg 2002;28:676-681.

9. Alio JL, Artola A, Ruiz-Moreno JM, Hassanein A, Galal A, Awadalla MA. Changes in keratoconic corneas after intracorneal ring segment explantation and reimplantation. Ophthalmology 2004;111:747-751.

10. Quantock AJ, Kincaid MC, Schanzlin DJ. Stromal healing following explantation of an ICR (intrastromal corneal ring) from a nonfunctional human eye. Arch Ophthalmol 1995;113:208-209.

11. Samimi S, Leger F, Touboul D, Colin J. Histopathological findings after intracorneal ring segment implantation in keratoconic human corneas. J Cataract Refract Surg 2007;33:247-253.

12. Ruckhofer J, Bohnke M, Alzner E, Grabner G. Confocal microscopy after implantation of intrastromal corneal ring segments. Ophthalmology 2000;107:2144-2151.

13. Twa MD, Ruckhofer J, Kash RL, Costello M, Schanzlin DJ. Histologic evaluation of corneal stroma in rabbits after intrastromal corneal ring implantation. Cornea 2003;22:146-152.

14. Fleming JF RA, Kilmer L, BurrisTE, Abbott RL, Schanzlin DJ. The intrastromal corneal ring, two cases in rabbits. J Refract Surg 1987;3:227-232.

15. Merayo-Lloves J, Blanco-Mezquita T, Ibares-Frias L, Fabiani L, Alvarez-Barcia A, Martinez-Garcia C. Induction of controlled wound healing with PMMA segments in the deep stroma in corneas of hens. Eur J Ophthalmol 2010;20:62-70.

16. Fowler WC, Chang DH, Roberts BC, Zarovnaya EL, Proia AD. A new paradigm for corneal wound healing research: the white leghorn chicken (Gallus gallus domesticus). Curr Eye Res 2004;28:241-250.

17. Bueno JM, Gualda EJ, Artal P. Analysis of corneal stroma organization with wavefront optimized nonlinear microscopy. Cornea 2011;30:692-701.

18. Glasser A, Troilo D, Howland HC. The mechanism of corneal accommodation in chicks. Vision Res 1994;34:1549-1566.

19. Martinez-Garcia MC, Merayo-Lloves J, Blanco-Mezquita T, MarSardana S. Wound healing following refractive surgery in hens. Exp Eye Res 2006;83:728-735.

20. Perez-Merino P, Parra F, Ibares-Frias L, Gallego P, Vazquez-Lasa B, Benito L, et al. Clinical and pathological effects of different acrylic intracorneal ring segments in corneal additive surgery. Acta Biomater 2010;6:2572-2579.

21. Ritchey ER, Code K, Zelinka CP, Scott MA, Fischer AJ. The chicken cornea as a model of wound healing and neuronal re-innervation. Mol Vis 2011;17:2440-2454.

22. Torquetti L, Ferrara G, Almeida F, Cunha L, Araujo LP, Machado $\mathrm{A}$, et al. Intrastromal corneal ring segments implantation in patients with keratoconus: 10-year follow-up. J Refract Surg 2014;30:22-26.

23. Ibares-Frías L, Gallego P, Cantalapiedra-Rodriguez R, Valsero MC, Mar S, Merayo-Lloves J, Martinez-Garcia MC. Validation of an experimental animal model for corneal additive surgery. J Clin Exp Ophthalmol 2014;5:360-369.

24. Ruckhofer J, Twa MD, Schanzlin DJ. Clinical characteristics of lamellar channel deposits after implantation of intacs. J Cataract Refract Surg 2000;26:1473-1479.

25. Fantes FE, Hanna KD, Waring GO 3rd, Pouliquen Y, Thompson KP, Savoldelli M. Wound healing after excimer laser keratomileusis (photorefractive keratectomy) in monkeys. Arch Ophthalmol 1990;108:665-675. 
26. Li T, Troilo D, Glasser A, Howland HC. Constant light produces severe corneal flattening and hyperopia in chickens. Vision Res 1995;35:1203-1209.

27. Torres RM, Merayo-Lloves J, Blanco-Mezquita JT, Gunther CP, Rodriguez G, Gutierez R, Martinez-Garcia C., et al. Experimental model of laser in situ keratomileusis in hens. J Refract Surg 2005;21:392-398.

28. Ibares-Frias L, Gallego P, Cantalapiedra-Rodriguez R, Valsero MC, Mar S, Merayo-Lloves J, Martinez-Garcia MC., et al. Tissue reaction after intrastromal corneal ring implantation in an experimental animal model. Graefes Arch Clin Exp Ophthalmol 2015;253:1071-1083.
29. Kwitko S, Severo NS. Ferrara intracorneal ring segments for keratoconus. J Cataract Refract Surg 2004;30:812-820.

30. Ferrara G, Torquetti L, Ferrara P, Merayo-Lloves J. Intrastromal corneal ring segments: visual outcomes from a large case series. Clin Experiment Ophthalmol 2012;40:433-439.

31. Ferrer C, Alio JL, Montanes AU, Perez-Santonja JJ, del Rio MA, de Toledo JA, et al. Causes of intrastromal corneal ring segment explantation: clinicopathologic correlation analysis. J Cataract Refract Surg 2010;36:970-977.

32. Wolter JR. Reactions of the cellular elements of the corneal stroma; a report of experimental studies in the rabbit eye. AMA Arch Ophthalmol 1958;59:873-881. 